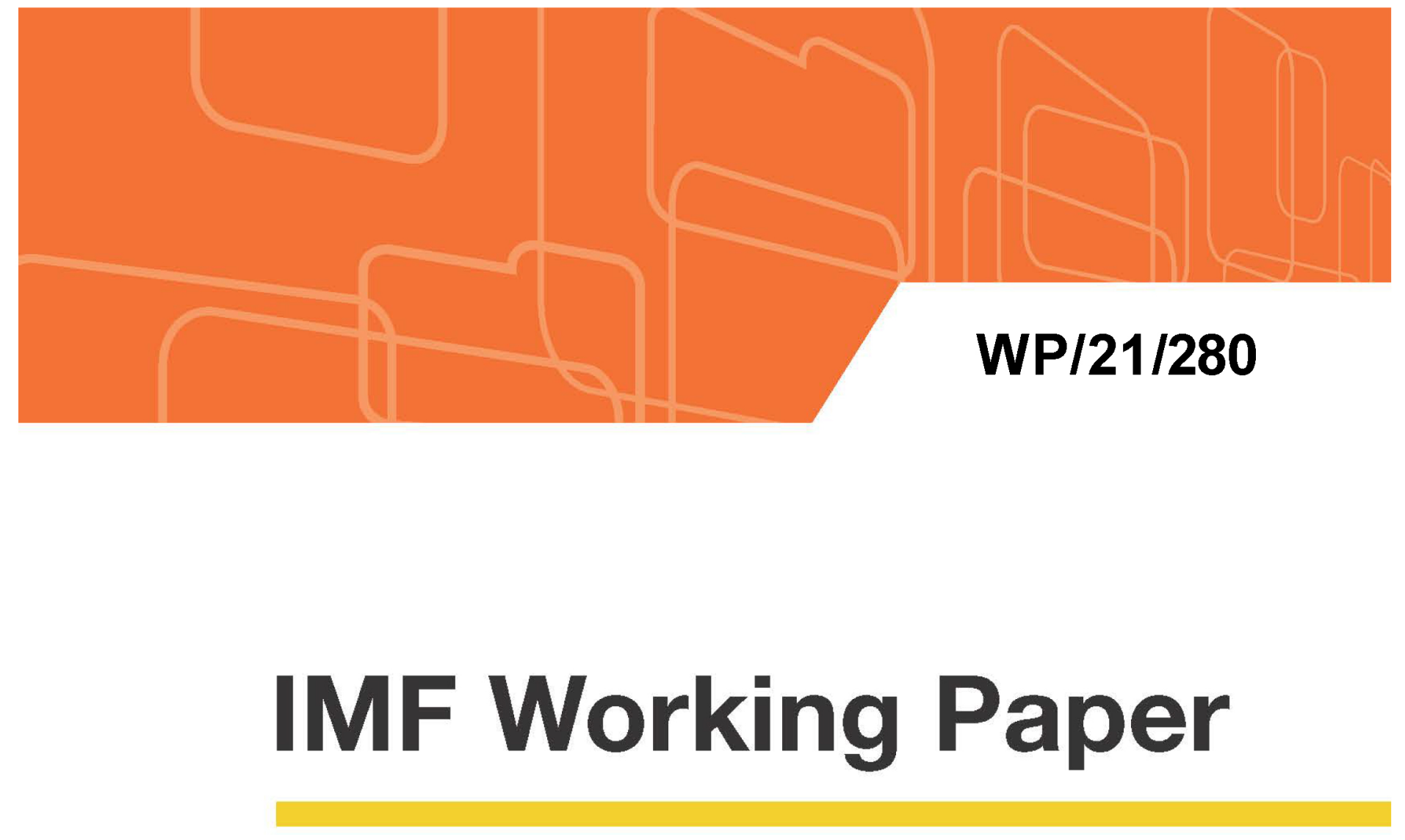

\title{
Global Climate Change Mitigation, Fossil-Fuel Driven Development, and the Role of Financial and Technology Transfers: A Simple Framework
}

by Johannes Wiegand

IMF Working Papers describe research in progress by the author(s) and are published to elicit comments and to encourage debate. The views expressed in IMF Working Papers are those of the author(s) and do not necessarily represent the views of the IMF, its Executive Board, or IMF management. 


\title{
IMF Working Paper
}

\author{
Strategy, Policy and Review Department
}

\section{Global Climate Change Mitigation, Fossil-Fuel Driven Development, and the Role of Financial and Technology Transfers: A Simple Framework}

\author{
Prepared by Johannes Wiegand ${ }^{1}$
}

November 2021

\begin{abstract}
IMF Working Papers describe research in progress by the author(s) and are published to elicit comments and to encourage debate. The views expressed in IMF Working Papers are those of the author(s) and do not necessarily represent the views of the IMF, its Executive Board, or IMF management.
\end{abstract}

\begin{abstract}
Climate financing and compensation have emerged as key themes in the international climate mitigtion debate. According to one argument in support of compensation, advanced economies (AEs) have used up much of the atmosphere's absorptive capacity, thus causing global warming and blocking a similar, fossil-fuel driven development path for emerging markets and developing economies (EMDEs). This paper develops a simple model of a sequential, fossil-fuel driven development process to discuss these issues systematically. The results suggest: (i) AEs have typically a stronger interest in climate change mitigation than EMDEs, (ii) from an equity perspective, compensation is called for only if EMDEs are relatively small; (iii) there can also be an efficiency case for compensation, however, with AEs buying EMDEs out of some of their GHG emissions; (iv) ultimately, a superior option - for both the world's climate and growth prospects - is the development of clean energy technologies by AEs and their transfer to EMDEs. The latter requires strong mitigation efforts by AEs even if EMDEs fail to play along initially.

JEL Classification Numbers: D62, F64, O13, Q54

Keywords: Development, Climate Change, Climate Change Mitigation, Climate Financing Author's E-Mail Address: jwiegand@imf.org

\footnotetext{
${ }^{1}$ The author is grateful to Emanuele Massetti, Gregor Schwerhoff and German Villegas Bauer for a careful review of the paper; to Alejandro Badel, Simon Black, Henrique Chociay, Florence Jaumotte, Kristina Kostial, Ian Parry, James Roaf, Manrique Sainz, Vimal Thakoor, Yunhui Zhang and other IMF seminar participants for helpful comments; and to Marisol Murillo for assistance with the production of the document.
} 
Table of Contents

Abstract

I. Introduction $\underline{4}$

II. The Basic Model $\underline{6}$

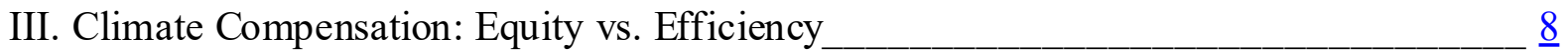

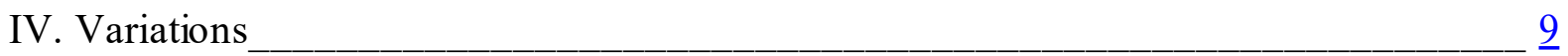

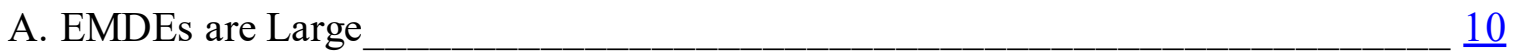

B. Some EMDEs are Disproportionately Vulnerable to Climate Change _______

V. Energy Efficiency, Clean Energy Technologies and Technology Transfers ____ 12

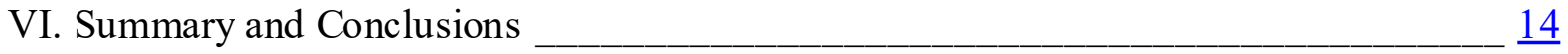

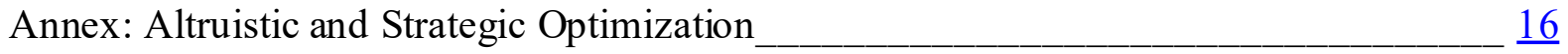

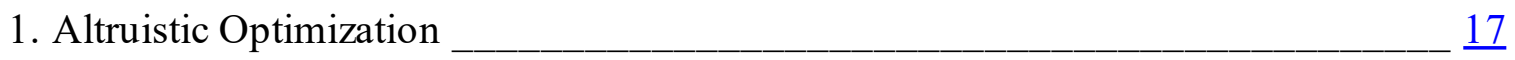

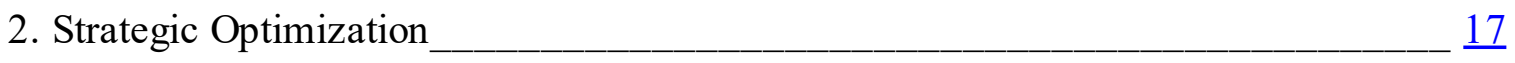

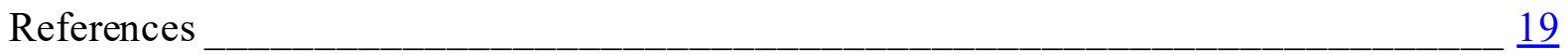

Figures

1. Fossil-Fuel Driven, Sequential Development ____ 1

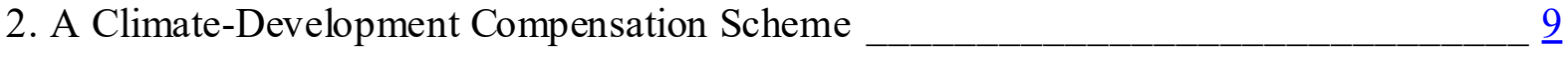

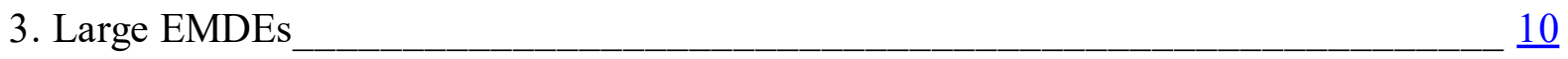

4. EMDEs Disproportionately Vulnerable to Climate Change__________________________

5. Adoption of Clean Energy Technologies __________________________ 


\section{INTRODUCTION}

"Climate financing"-financial assistance to support lower-income countries with implementing climate-related policies - is playing an increasingly prominent role in the international climate debate. Among other things, climate financing is enshrined in the Paris climate accord, which contains a clause that advanced economies would provide US $\$ 100$ billion annually for low-income countries - the terms of this commitment are currently being reworked in the context of the COP2 6 climate conference. ${ }^{2}$ What the term "climate financing" covers is not always entirely clear, however: it has various connotations and dimensions that relate to different climate policies and different shortcomings that climate financing is meant to address.

$>$ One dimension is what financing is for: adaptation to climate change or climate change mitigation. Adaptation seeks to contain the economic and social repercussions of climate change. Mitigation aims at reducing (and/or offsetting) greenhouse gas emissions, and therefore at limiting global warming.

A second dimension is the shortcoming that climate financing addresses.

- Financing in a narrow sense covers a liquidity need that, if not satisfied, would prevent countries from taking adequate climate policies. Lack of financing in a narrow sense reflects market failures, an example are thin and incomplete insurance markets for climate risk. Such failures could, at least in principle, be addressed through structural reforms. In practice, however, such reforms can be cumbersome and require a long time to bear fruit - time that is often not available when it comes to climate policies. Financing in a narrow sense is arguably most relevant for climate change adaptation (IMF, 2019a). By contrast, good climate change mitigation policies often generate financing by themselves: carbon taxes, for example, raise (rather than absorb) fiscal revenues (IMF, 2019b).

- Another potential use of climate financing is for compensation. Compensation reimburses lower-income countries for damage inflicted on them by the greenhouse gas (GHG) emissions of advanced economies (AEs). Different from financing in a narrow sense, compensation contains a transfer element. While compensation can be unconditional, in practice it is often coupled with policy objectives: AEs extend transfers in exchange for emerging markets and developing economies (EMDEs) adopting specific climate measures. Climate compensation can be delivered through

\footnotetext{
2 "The Convention, the Kyoto Protocol and the Paris Agreement call for financial assistance from Parties with more financial resources to those that are less endowed and more vulnerable. This recognizes that the contribution of countries to climate change and their capacity to prevent it and cope with its consequences vary enormously." See https://unfccc.int/topics/climate-finance/the-big-picture/introduction-to-climate-finance. OECD (2020) estimates that climate financing was close to US\$80 billion in 2018, with a grant element of about 10 percent. What precisely counts as climate financing for this purpose is disputed, however, with disagreements relating to whether climate financing needs to be additional (as opposed to re-declaring existing flows for climate purposes), and to the extent to which private financing flows are/should be included in the aggregate.
} 
various mechanisms that include grants, debt relief, or grant elements in concessional lending. ${ }^{3}$

This paper seeks to analyze the links between development, climate change mitigation policies, and compensation for EMDEs in a systematic manner-hence the paper is not about financing in a narrow sense. It argues along a simple model in which two country blocks, AEs and EMDEs, develop sequentially. The paper contains two scenarios. The first part (sections II.-IV.) analyzes a traditional development process in which the built-up of production capacity requires burning fossil fuels and therefore emitting GHGs. AEs, by developing first, use up a portion of the atmosphere's absorptive capacity for GHGs, which affects the development prospects of EMDEs. Within this setting, answers can be derived inter alia to the following questions:

What does the sequential development pattern imply for climate change mitigation? Are mitigation policies that are desirable for AEs also desirable for EMDEs?

$>$ Under which circumstances is there an equity case for compensating EMDEs?

Is there also an efficiency case for compensation-i.e., is there scope for a mutually beneficial scheme where AEs transfer a part of their wealth to EMDEs, in return for EMDEs abandoning the pursuit of fossil fuel driven development?

$>$ How do factors such as the relative size of AEs vs. EMDEs or asymmetric cost from climate change (e.g., EMDEs in already hot regions are more vulnerable to climate change than AEs in temperate regions) affect mitigation policies and the equity/efficiency cases for compensation?

The world economy has started to move away from purely fossil-fueled development, however, as GHG-free energy technologies have become more widespread and cost competitive. The paper's second part (section V.) pays tribute to these developments and modifies the model to analyze how clean technologies affect development patterns, climate policies of AEs and EMDEs, and the case for financial compensation.

The paper relates to several themes discussed both in the global climate policy debate and the academic literature. First, it analyzes tradeoffs between climate change mitigation and development. ${ }^{4}$ Second, the paper contributes to the debate on the feasibility of international climate agreements. ${ }^{5}$ Third, it analyzes several aspects of climate compensation, both from a

\footnotetext{
${ }^{3}$ Compensation schemes can also serve both objectives. One of the most prominent recent proposals—Rajan's (2021) global carbon incentive - combines redistribution for equity purposes with an incentive scheme to reduce GHG emissions.

${ }^{4}$ See Clarke and others. (2014) for an analysis at a global scale. For a study of the cost to reduce greenhouse gas emissions in the United States see Gillingham and Stock (2018). IMF (2020) also contains a valuable discussion.

${ }^{5}$ Scott Barrett and Valentina Bosetti (among others) has made several important contributions to this topic, examples include Scott Barrett (2016) and Bosetti and others (2013). See IMF (2021) for a practical proposal.
} 
'loss and damage' (James and others, 2014) and from an efficiency (pareto improvement) perspective. Finally, the paper discusses technology diffusion as an alternative to global climate mitigation agreements. ${ }^{6}$

\section{THE BASIC MODEL}

Starting point is an energy-based development pattern in which the built-up of production capacity involves burning of fossil fuels and emitting greenhouse gases:

$$
P_{i}=f\left(e_{i}\right), f^{\prime}\left(e_{i}\right)>0, f^{\prime \prime}\left(e_{i}\right)<0
$$

(1) captures a type of environmental Kuznets curve: the production capacity $P$ that country $i$ builds up over time is a function of its cumulative GHG emissions $e_{i}$. $e$ is a stock and is irreversible: once emitted, GHG emissions stay in the atmosphere. ${ }^{7}$ The development dividend from burning fossil fuels is largest at the early stages of development when countries develop heavy industries etc., it shrinks thereafter.

$$
C_{i}=g(E), \quad g^{\prime}(E)>0, g^{\prime \prime}(E)>0, E=\sum_{j} e_{j}
$$

Greenhouse gas emissions trigger non-linear cost: almost negligible with low GHG emissions, rising disproportionately as the concentration of GHGs in the atmosphere increases. Further, cost is a function of all countries' emissions $(j=1, \ldots J)$, not only the emissions of country $i$ : GHG emissions are a global negative externality. The non-linearity assumptions in (1) and (2) - decreasing returns to development from GHG emissions, disproportionately increasing costs - are critical for deriving most results below. To ensure the existence of an equilibrium outcome with positive GHG emissions, the following technical conditions also need to hold: $f(0)=g(0)=0$, and $f^{\prime}(0)>g^{\prime}(0)$.

The following considers two country blocks: advanced economies that develop first, and emerging markets and developing economies that develop second. Formally the model is thus a two-stage game with two players. ${ }^{8}$ In the reference model, AEs and EMDEs are of equal size, the assumption is modified later. $f\left(e_{i}\right)$ is parameterized as $f\left(e_{i}\right)=e_{i}^{\alpha}$ with $0<\alpha<1$, while $g(E)$ is parameterized as $g(E)=E^{\beta}$ with $\beta>1$. For illustrative purposes, the following graphs set the parameters at $\alpha=0.5$ and $\beta=2$. Most results do not depend on the precise parameter values, however, as long as $\alpha$ and $\beta$ comply with the non-linearity conditions above.

\footnotetext{
${ }^{6}$ See Acemoglu and others (2016) or Philipp Barrett (2021) for recent contributions.

${ }^{7}$ This formulation is different from — but consistent with — the traditional environmental Kuznets curve, which is typically formulated in terms of annual emissions. See Shahbaz and Sinha (2019) for a recent survey.

${ }^{8}$ The reduction to two country groups and the sequential development pattern are significant simplifications. Among other things, they imply that only one country group emits GHGs at any given time, which eliminates collective action problems from the analysis. Empirically, AEs accounted for almost all cumulative emissions until about 1950. Since then, the share of EMDEs has increased steadily to about 35 percent today - see https://ourworldindata.org/contributed-most-global-co2.
} 
Figure 1 shows the basic results. As AEs develop, they emit GHGs. Emissions eventually reach a saturation point $\bar{e}_{A E}$ where the marginal benefit from generating additional production capacity no longer exceeds the marginal cost from more GHG emissions, i.e., $f^{\prime}\left(\bar{e}_{A E}\right)=g^{\prime}\left(\bar{e}_{A E}\right)$. At this point, fossil-fuel driven development in AEs comes to an end: additional growth would be desirable only if achieved without adding more GHGs to the atmospherehence it is in the interest of AEs to implement climate mitigation policies that arrest the emission of GHGs. ${ }^{9}$

Now EMDEs enter the frame: they start developing once AEs have reached their saturation point. Returns from GHG

Figure 1. Fossil-Fuel Driven, Sequential Development

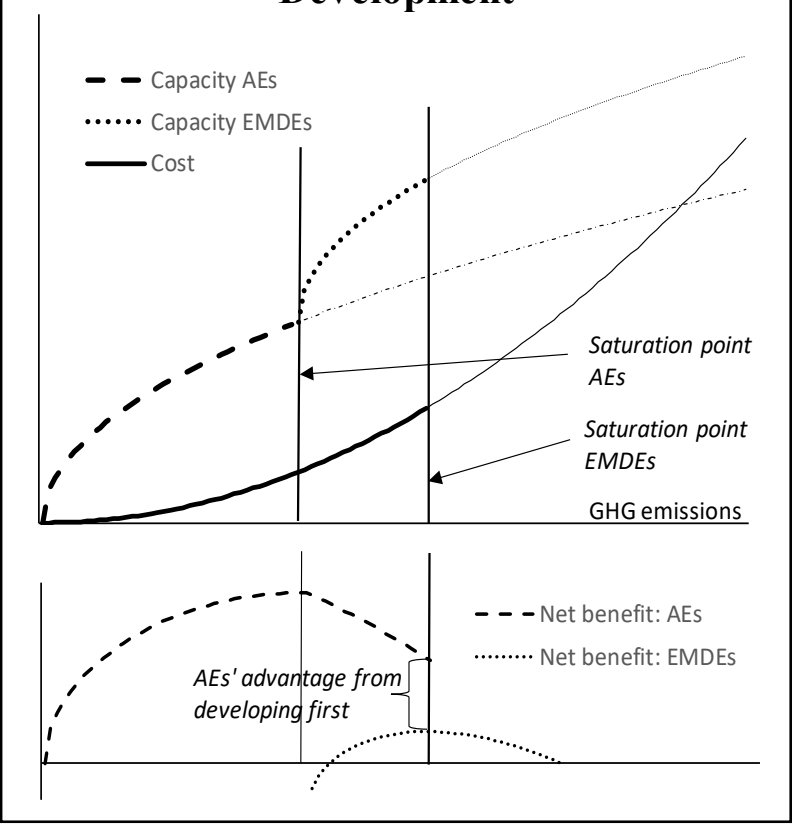
emissions are high at the early stages of development. Hence, and different from AEs, EMDEs still find profitable development opportunities - notwithstanding that realizing these opportunities generates additional GHG emissions and therefore increases the cost from global warming. EMDEs have an incentive to abandon fossil fuel driven development only once they have reached their saturation point at $f^{\prime}\left(\bar{e}_{E M D E}\right)=g^{\prime}\left(\bar{e}_{A E}+\bar{e}_{E M D E}\right)$.

Several features of this two-stage climate-development game are worth noting.

At the AEs' saturation point, AEs will implement mitigation policies, given that for them, every additional unit of GHGs is harmful. They would like EMDEs to do the same, but EMDEs will be unwilling to do so, as this would mean foregoing profitable development opportunities.

More generally, EMDE development is painful for AEs: it adds cost from more GHG emissions and hence global warming, without generating additional benefits for AEs. ${ }^{10}$

Still, AEs end up in a better position than EMDEs. At the EMDEs' saturation point-when global GHG emissions come to an end-AEs have generated higher production capacity

\footnotetext{
${ }^{9}$ AEs optimize individually, i.e., they maximze their own net benefit without regard for the net benefits of EMDEs. Moreover, AEs do not endogenize EMDEs' behavior. This latter implies a degree of myopia: strategically optimizing AEs would anticipate the impact that their own emissions have on EMDEs' emitting behavior, and factor this into their own mitigation decisions. While strategic optimization may seem the more appealing concept on theoritcal grounds, assuming it here seems a rather extreme stretch, given the very long duration of the development process (measured in decades rather than years), the typically much shorter time horizon of poliymakers, and large uncertainty surrounding the game's future paramteters (e.g., technological change as discussed in section V. alters the game's configuration fundamentally). See the Annex for a comparison of outcomes under individual, altruistic and strategic optimization.

${ }^{10}$ This feature triggers the kink in the AE's net benefit curve at their saturation point.
} 
and have emitted more GHGs than EMDEs, while both types of countries suffer the cost from global warming equally. As a result, and as depicted in the lower panel of Figure 1, the net development benefit - i.e., productive capacity minus the cost from global warming, $P_{i}\left(e_{i}\right)-C_{i}(E)$ - is larger for AEs than for EMDEs.

Note that, with the exception of AEs developing first, AEs and EMDEs are modeled symmetrically: they have same size, exhibit the same vulnerability to climate change, and the relationship between GHG emissions and development is identical for both types of countries. Hence the advanced economies' first-developer advantage accounts for the entire result. Developing first allowed AEs to use a limited resource that is critical for fossil-fuel driven development: the atmospheres' absorptive capacity. When AEs are done developing, only scraps of this resource are left for EMDEs.

\section{Climate Compensation: Equity vs. EfFiciency}

The previous section suggests an equity case for compensation: to equalize net benefits, AEs would have to transfer an amount to EMDEs that reimburses the latter for the cost that AEs caused by using up the atmosphere's absorptive capacity. A different question is whether there is also an efficiency or pareto-improvement case for compensation. Could AEs offer EMDEs a scheme that makes both sides better off? Put differently, could it be in the AEs' (non-altruistic) interest to transfer part of their wealth to EMDEs to contain climate change?

Such a transfer would be coupled with a policy objective: AEs would demand a commitment from EMDEs to abandon fossil-fuel development. Whether such a scheme is possible-i.e., beneficial for both sides - requires comparing marginal (rather than absolute) benefits. The condition for a mutually profitable transfer is:

$$
\underbrace{g^{\prime}\left(\bar{e}_{A E}+e_{E M D E}\right)}_{(A)}>\underbrace{f^{\prime}\left(e_{E M D E}\right)-g^{\prime}\left(\bar{e}_{A E}+e_{E M D E}\right)}_{(B)}>0
$$

(A) is the cost of one additional unit of GHG emissions for AEs, (B) the net benefit of one additional unit of GHGs for EMDEs. If (A) exceeds (B), AEs could offer an amount larger than (B) but smaller than (A) to EMDEs to abandon fossil-fuel development. ${ }^{11}$

Figure 2 illustrates the key features of a compensation scheme.

First, a key result is that a mutually beneficial compensation scheme always exists.

EMDEs obtain (per definiton) a near-zero net benefit from the last unit of GHGs they emit, while the same unit imposes non-zero cost on AEs. It is therefore in the interest of both parties that AEs buy EMDEs out of that unit (and out of any other unit to the left of $\bar{e}_{E M D E}$ where (3) holds). The result is a negotiated outcome as depicted in Figure 2.

\footnotetext{
${ }^{11}$ Note that (B) needs to be positive for the existence of a compensation scheme, as with a negative (B), EMDEs would stop emitting GHGs by themselves (i.e., without being offered compensation).
} 
Second, even with a compensation scheme, EMDEs would exploit the most profitable development opportunities and expand GHG emissions beyond the saturation point of AEs, before agreeing to be bought out of their remaining emissions. While EMDEs develop, the policy disconnect described in the previous section would apply: AEs would seek to mitigate climate change, while EMDEs would not (yet). ${ }^{12}$

The exact net development benefit for AEs and EMDEs cannot be determined ex-ante with a climate compensation scheme, as it depends on the outcome of a negotiation. The maximum amount that AEs are prepared to pay in order to buy EMDEs of out their GHG emissions exceeds the minimum amount that

Figure 2. A Climate-Development Compensation Scheme

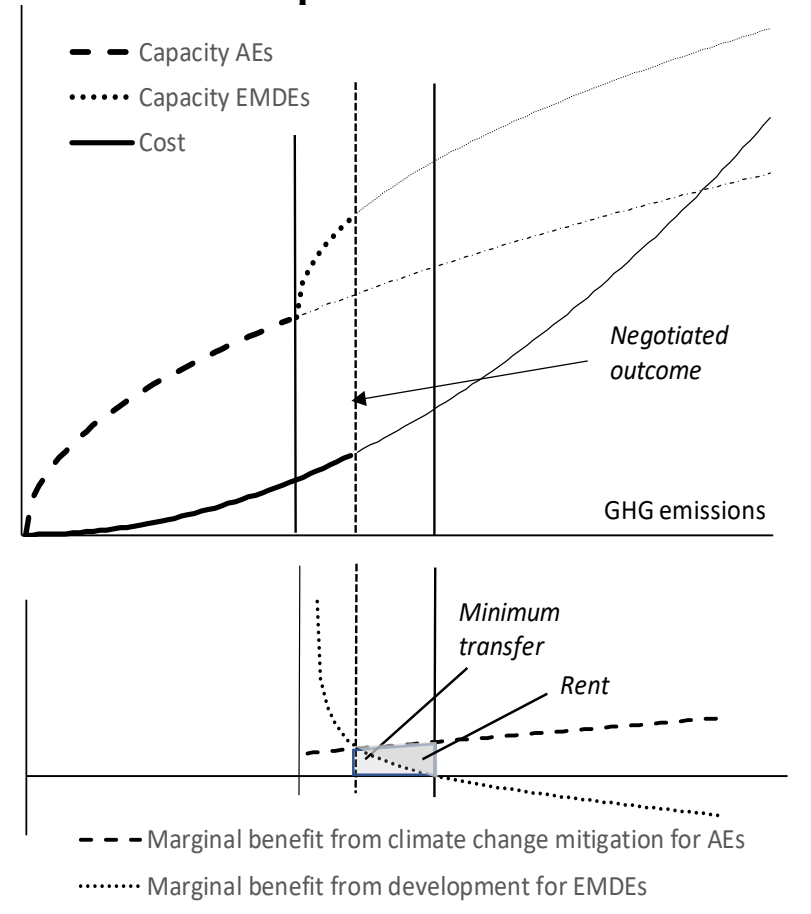

Note: the lower panel is not drawn to scale.

EMDEs require to abandon fossil-fuel driven development. The difference between these two amounts is a rent, which could be acquired by either side. ${ }^{13}$

\section{VARIATIONS}

The results thus have been derived assuming strict symmetry between AEs and EMDEsother than the sequential nature of the development process. This section modifies this assumption in two ways.

First, size symmetry is dropped. Emerging markets and developing economies host a far larger share of the world's population than advanced economies ( 86 percent according to

\footnotetext{
12 With the exponential parameterization of (1) and (2) and strictly sequential development, $f^{\prime}\left(e_{E M D E}\right)=\frac{\alpha}{\left(e_{E M D E}\right)^{1-\alpha}}$, which for $\alpha<1$ converges to infinity as $e_{E M D E}$ converges to zero. As a consequence, (3) cannot hold just to the right of AEs' saturation point. The result-EMDEs stretch their emissions beyond the AEs' saturation point —also holds more generally, however, as long as AEs and EMDEs are symmetric. As EMDEs start developing later than AEs, the marginal benefit from building up an additional unit of production capacity is higher for EMDEs than for AEs at any level of aggregate GHG emissions. The opportunity cost for AEs from arresting their own GHG emissions are therefore lower than the cost of a compensation scheme with EMDEs, implying AEs would always implement their own mitigation policy first (i.e., at lower aggregate GHG emissions).

${ }^{13}$ The net benefit levels for AEs and EMDEs at $\bar{e}_{E M D E}$ depicted in Figure 1 are lower bounds for net benefit levels in the negotiated outcome. Thus, the position of EMDEs relative to AEs could improve, remain the same or even deteriorate as a result of the negotiation.
} 
the IMF's World Economic Outlook). If all EMDEs were to embark on a similar, fossilfuel driven development path as AEs did in the past, the consequences for GHGs emissions and the world's climate would be more severe than the symmetric specification implies.

Second, the assumption of an identical cost function (2) is modified. Many-although not all-EMDEs are located in regions that are already disproportionately hot and susceptible to climate damage. Additional global warming is likely to hurt such countries more than countries in temperate regions (IMF, 2017). This section analyzes the impact of such modifications on climate mitigation and compensation policies. ${ }^{14}$

\section{A. EMDEs are Large}

Figure 3 triples the size of EMDEs relative to AEs. The larger a country or country block, the more profitable development opportunities exist, hence the EMDEs' development curve (1) shifts outward.

Some results from the basic specification persist: relative to their size, advanced economies build up more productive capacity and emit more GHGs than EMDEs. AEs would also buy EMDEs out of some of their GHG emissions; with larger EMDEs, the size of the compensation scheme would increase.

The key difference to the symmetric case is that the AEs' advantage from developing first unravels. As larger EMDEs can exploit more development opportunities, they reach their saturation point later, i.e., at a higher level of GHG emissions than smaller EMDEs. The cost that these additional emissions place on AEs reduces the net development benefit for the latter - if EMDEs are large enough, it can in fact unravel entirely.

Put differently, while AEs imposed cost from GHG emissions on EMDEs during their development process, the cost that

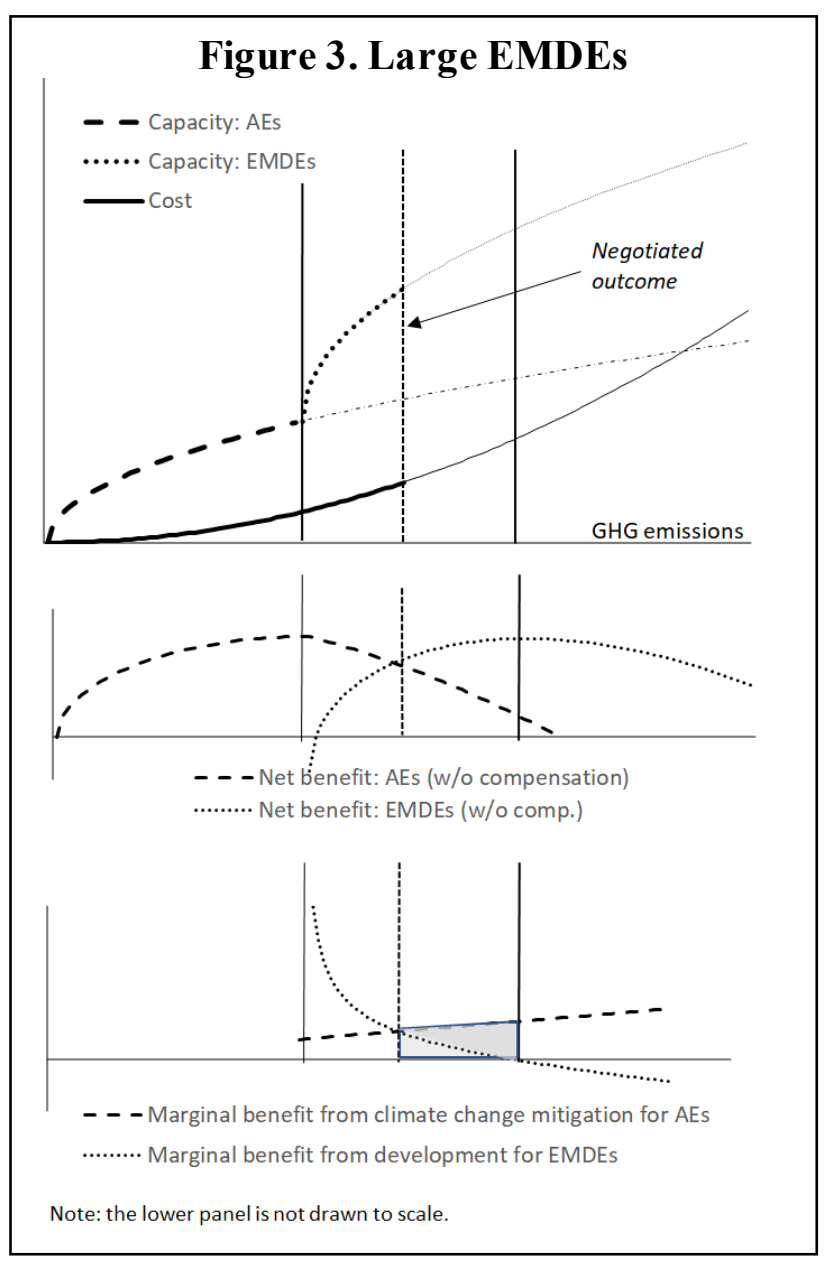

${ }^{14}$ Another variation that maybe suggests itself is modifying the $\alpha$ and $\beta$ coefficients in (1) and (2). However, this does not yield many insights. The qualitative results remain unchanged; in general, a more convex cost function (higher $\beta$ ) and/or more rapidly declining returns from GHGs emissions (lower $\alpha$ ) constrain the EMDEs' space for fossil-fueled development. 
large EMDEs would force on AEs if they followed the same development path could be even larger. This weakens the equity case for climate compensation.

\section{B. Some EMDEs are Disproportionately Vulnerable to Climate Change}

Figure 4 doubles the cost from global warming for EMDEs relative to AEs, to reflect that some EMDEs are especially vulnerable to climate change. ${ }^{15}$

Disproportionate climate vulnerability leaves EMDEs with little room to pursue fossil-fuel driven development, as the damage from additional GHG emissions would overwhelm the benefits from increasing production capacity rapidly. This feature amplifies the AEs' firstdeveloper advantage and strengthens the equity case for compensation. ${ }^{16}$ However, it also places climate vulnerable EMDEs in a weak negotiation position: if AEs anticipate that climate vulnerable EMDEs would take significant mitigation measures also without being compensated, any scheme to buy EMDEs out of part of their GHG emissions would be small. ${ }^{17}$

Clearly this result does not apply to all EMDEs alike: some EMDEs are located in regions especially vulnerable to global warming, others are not. It is best interpreted in conjunction with the finding from the previous variation: EMDEs are unlikely to be a homogeneous group when it comes to cooperation with advanced economies on climate change. The interests of smaller EMDEs located in climate-vulnerable regions may be quite

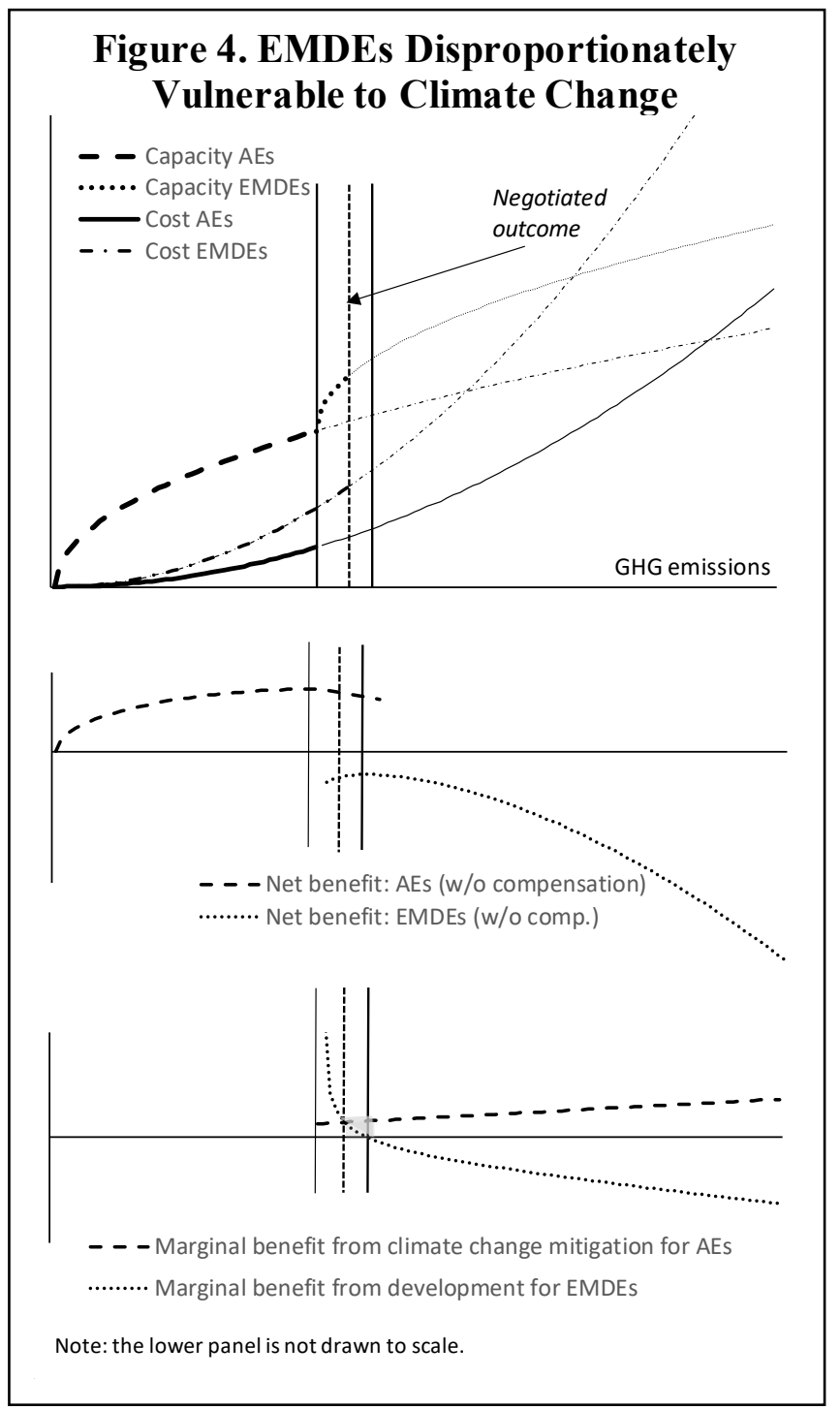

15 Thus, a different cost function applies to EMDEs than to AEs. In figure $4 C_{E M D E}$ is parameterized as $2 E^{\beta}$.

${ }^{16}$ With different vulnerabilities to climate change, the difference between AEs' and EMDE's net benefits (precompensation) encompasses not only differences in the built-up of production capacity, but the fact that EMDEs suffer higher cost from GHG emissions than AEs.

${ }^{17}$ With EMDEs that are especially vulnerable to climate change, one result from the previous section-AEs would implement their own mitigation policies first before buying out EMDEs (Fn 11) - does not necessarily hold any longer if one also drops the assumption of a strictly sequential development process. In this case, it can be more expensive for AEs to end their own GHG emissions than buying climate vulnerable EMDEs out of theirs. 
well aligned with advanced economies - hence it may be possible to agree on a coordinated mitigation effort in exchange for relatively modest amounts of compensation. By contrast, buying large EMDEs located in temperate regions out of their greenhouse gas emissions is likely to be significantly more costly and challenging.

\section{EnERgY EFFICIENCY, CLEAN ENERGY TECHNOLOGIES AND TECHNOLOGY TrANSFERS}

Finally, this section analyzes the impact of technological progress on climate and development prospects and policies. Technological progress has several dimensions that can be relevant in this context.

One phenomenon - that has been unfolding since the onset of the industrial revolution - are improvements in energy efficiency: a given unit of output can be produced with less energy input. While raising energy efficiency reduces greenhouse gas emissions in the short term, it does not arrest emissions in the longer term - at least not if energy use remains based on burning fossil fuels. More energy efficiency increases the return on energy use and therefore shifts the development curve (1) outward, which, in turn, means that development opportunities become profitable that otherwise would not have been realized. ${ }^{18}$ Ultimately this results in both the built-up of higher production capacity and higher GHG emissions.

A different type of progress is the replacement of fossil fuels with clean energy technologies, or more precisely: technologies that allow increasing production capacity without a net increase in GHG emissions. ${ }^{19}$ This type of progress has been made large strides in recent years and decades, with clean technologies becoming cost competitive in sectors such as power generation or industry — see IRENA (2021) for a description and analysis of recent trends.

The transition is sketched in Figure 5. It assumes that AEs, as they approach their saturation point for GHG emissions switch to a clean energy technology. The technology is represented by a cost function with lower marginal cost than the continued emissions of GHGs. ${ }^{20}$ Moreover, the technology is also available to EMDEs, i.e., there is a positive externality in the form of a technology transfer. At the same time, and different from GHG emissions, the new technology does not produce negative externalities. ${ }^{21}$

The switch to a clean energy technology removes the constraints that GHG emissions place on development. The saturation points for both AEs and EMDEs-but especially for

\footnotetext{
${ }^{18}$ In this model setting, raising energy efficiency is formally identical with increasing an economy's size.

${ }^{19}$ This could include a switch to renewable energies, clean fuels, or the move to a 'circular economy', where GHG emissions are extracted from the atmosphere and recycled.

${ }^{20}$ In this graph the cost function representing the clean technology is linear. However, the assumption is not critical, key is that at AEs' saturation point, the marginal cost associated with this technology is less than those from emitting more GHGs.

${ }^{21}$ The cost of using the technology is thus born only by the country that is expanding production capacity. Such cost could, e.g., consist of the opportunity cost of land absorbed by renewable energy technologies.
} 
EMDEs - shift to the right, thus, both country blocks can build up more production capacity than would have been possible with burning fossil fuels.

Clearly there is no longer an efficiency case for a compensation scheme: EMDEs do not need to be bought out of their GHG emissions, as with the adoption of clean energy technologies they stop emitting GHGs by themselves.

The model still shows a first-developer advantage for AEs, however, suggesting that an equity case for compensation persists. The reason is rooted in the Kuznets curve pattern of development that starts with an energy intensive phase when countries build up sectors such as heavy industry. AEs were able to pass some cost from this early, energy intensive phase to EMDEs by emitting GHGs into the atmosphere. EMDEs will not have this opportunity; instead, they have to bear the cost from generating and using energy themselves. Note that the size of first-developer advantage shrinks though as the marginal cost of clean energy generation fall.

Overall, these results point to the development and transfer of clean energy technologies being a superior outcome than a financial climate compensation scheme. Technology transfer results in less GHG emissions and higher net development benefits, for both AEs and EMDEs. The process of how clean technologies are being developed and adopted is not modeled here, however, AEs clearly have a strong incentive to invest into such technologies as they approach their GHG saturation point: it is the only option for them to grow further. ${ }^{22}$ Allowing EMDEs to use these technologies helps both the AEs' own case-by preventing further GHG emissions - and the case of EMDEs. Put differently, AEs' development process started with the production of a 'public bad': GHG emissions, whose cost were partly born by EMDEs. The detrimental impact of this 'bad' can be undone - at least party - by now producing a public good: clean technologies and their transfer to EMDEs.

Two qualifying remarks seem in order.

\footnotetext{
22 For a closer and granular analysis of the technology development and adoption process see the recent contribution of Philipp Barrett (2021), who analyzes technology diffusion within a regional integrated assessment model of the global economy and studies outcomes if only a subset of countries adopts mitigation policies. He finds sizeable global mitigation gains regardless, as technological diffusion dissuades dirty innovations that would otherwise spread.
} 
First, transfer of clean energy technologies is less of a clearly defined policy than financial transfers. Some technology diffusion happens also without policy intervention; supporting policies cover measures as different as reducing trade barriers, resolving intellectual property issues, financing for low-income countries, and initiatives to advise EMDEs on technology-related issues. ${ }^{23}$ However, an indispensable component of any global technology transfer policy are ambitious mitigation measures in advanced economies, to create demand for low-carbon technologies and incentivize technology deployment. Such measures include credible emission targets, steps that instigate relative price changes between high- and low-carbon technologies such as carbon pricing, and support for climate-related research and development (IMF, 2020).

Second, while financial and technology transfers have been presented as alternatives in this and the previous sections, the unevenness of technological progress means that, in practice, there can be a need for both. As mentioned earlier, the development of clean technologies is more advanced in some sectors - such as power generation or industry - than in others-long-distance transport or buildings. For the more advanced sectors, creating the conditions for a rapid adoption of clean technologies by EMDEs appears a feasible (and important) near-term objective. However, technology transfers by themselves may not suffice for a comprehensive global mitigation strategy — at least not yet.

\section{SUMMARY AND CONCLUSIONS}

This paper sketched a simple model in which advanced economies develop first and emit greenhouses gases into the atmosphere - an irreversible process that interferes with the development prospects of emerging markets and developing economies. Although the model is simplicity itself, it reproduces several features of the current international climate policy debate and offers some perspectives: ${ }^{24}$

First, the model provides a rationale why the interests of advanced economies and emerging and developing economies can diverge when it comes to climate change mitigation.

Advanced economies may be approaching a point where the cost from additional greenhouse gas emissions outweighs the growth benefits, while for (some) EMDEs this point may still be some way off. This feature supports proposals to differentiate mitigation requirements by development needs, for example by specifying somewhat less stringent demands on EMDEs that participate in an international carbon price floor arrangement (IMF, 2021).

\footnotetext{
${ }^{23}$ See Diringer (2009) for a (somewhat dated but still relevant) overview. Probst and others (2021) summarize recent trends in the innovation and diffusion of climate change mitigation technologies, while Miyamoto and Takeuchi (2019) provide empirical evidence on the link between mitigation ambition in advanced countries and technology diffusion to emerging markets.

${ }^{24}$ The model could be refined in many ways that would make for a richer and granular analysis, and potentially help obtain additional insights. One is modeling AEs and EMDEs as coalitions of heterogenous countries rather than monolithic blocks Another is assuming a staggered development process - with EMDEs starting to emit GHGs before AEs reach their saturation point - rather than assuming a strictly sequential development pattern. These refinements are left to future research (and to more capable modelers).
} 
Second, the model demonstrates that there is a case for climate compensation-a principle enshrined into the Paris climate agreement. In fact, there can be more than one.

The equity case for compensation is unconditional and reflects the fact that AEs secured an advantage over EMDEs by exploiting and using up much of the atmosphere's absorptive capacity during their development process. A clear equity case exists only if EMDEs are modestly sized relative to AEs, however, as fossil-fuel driven development by large EMDEs can also impose large cost on AEs.

Separate from the equity case, there can be an efficiency case for climate compensation - at least as long the EMDEs' development pattern is linked to burning fossil fuels. The damage that EMDEs' GHG emissions place on AEs can exceed then the benefits that EMDEs extract themselves from pursuing fossil-fuel driven development. In this case, it makes sense for both parties if AEs buy EMDEs out of part of their emissions. The case for such an arrangement becomes the stronger the larger EMDEs are relative to AEs. It becomes weaker though when EMDEs are especially vulnerable to climate change, as vulnerable economies have a stronger interest in mitigating climate change on their own (i.e., they do not require compensation). It also becomes weaker with the development of cost-competitive clean energy technologies that can be used by EMDEs.

Overall, the equity and the efficiency cases for compensation are motivated differently and apply in different circumstances - sometimes the cases are diametrically opposed. This suggests treating them as two separate policy issues. Equitable compensation is primarily for smaller, climate-vulnerable states, and should be either unconditional or have adaptation measures as policy counterpart (i.e., measures that benefit the recipient but not the donor country). Efficient compensation would be part of an international climate change mitigation agreement between AEs and large EMDEs.

Third, the development of clean energy technologies and technology transfer to EMDEs is, ultimately, superior to financial compensation schemes. Clean energy is a game changer, as it allows for economic development without incurring more cost from GHG emissions. Advancing the development of such technologies should be a high priority for AEs that reach the limits of fossil-fuel driven growth. Moreover, it is in the interest of AEs to ensure that EMDEs can use these technologies also, as this would eventually dissolve the climatedevelopment conundrum and enhance growth prospects for both AEs and EMDEs. Put differently, by disseminating clean energy technologies, AEs would be providing a global public good.

This result underscores that it should be in the AEs' strong interest to pursue mitigation policies even if EMDEs are not playing along immediately — as absent such policies, the incentives to develop and deploy clean technologies are lacking. 


\section{AnNeX: Altruistic AndSTrategic OPTIMiZATION}

The paper models development and GHG emissions as a two-player, two-stage game where one player (advanced economies) has a first-mover advantage over the other (emerging economies). In this setting, the optimizing behavior of the first player is pivotal in determining the game's outcome. The base model assumes that AEs optimize independently from EMDEs, which translates into a simple first-order condition

$$
f^{\prime}\left(\bar{e}_{A E}^{i n d}\right)=g^{\prime}\left(\bar{e}_{A E}^{i n d}\right)
$$

AEs stop emitting GHGs when the cost that their own emission generate exceed the corresponding development benefit (ind denotes independent optimization). This annex sketches two alternatives:

$>$ Altruistic optimization. AEs seek to maximize the joint net development benefit for both, EMDEs and themselves. This comparison identifies the biases that sequential, fossil-fuel driven development triggers: over-development of AEs, under-development of EMDEs, and excessive GHG emissions overall.

$>$ Strategic optimization. AEs maximize their net development benefit while anticipating EMDEs' subsequent emissions behavior — similar to the behavior of the leader in a Stackelberg duopoly game. While strategic optimization may seem theoretically more appealing than independent optimization - the latter implies a degree of myopia on behalf of AEs - it seems rather far-fetched in this context, given the very long time horizon of the development game, the (typically) much shorter horizons or policymakers, and large uncertainty that renders future conditions difficult to anticipate and endogenize. ${ }^{25}$

Note that the EMDE's behavior is the same in all three scenarios: EMDEs optimize the development-GHG emission tradeoff while taking into account the amount of GHGs already in the atmosphere. This translates into the first-order condition

$$
f^{\prime}\left(\bar{e}_{E M D E}\right)=g^{\prime}\left(\bar{e}_{A E}+\bar{e}_{E M D E}\right)
$$

which, in turn, implies

$$
-1<\partial \bar{e}_{E M D E} / \partial \bar{e}_{A E}<0
$$

a higher saturation point for AEs implies a less-than-proportionate reduction in equilibrium GHG emissions by EMDEs, and therefore a less-than proportionate increase in overall equilibrium emissions. ${ }^{26}$

\footnotetext{
${ }^{25}$ For example, anticipating a technology switch as discussed in section V. would alter the behavior of strategic AEs.

${ }^{26}$ As per (1) and (2), $g$ ' increases to the right of EMDEs' saturation point while $f$ ' decreases. For (A2) to hold, a higher saturation point for AEs thus implies lower equilibrium GHG emissions by EMDEs. Lower EMDE emissions also increase $f^{\prime}$, however, hence the offsetting reduction in EMDE emissions must be less than the increase in AE emissions.
} 


\section{Altruistic Optimization}

With altruistic optimization, AEs maximize overall net benefits for both EMDEs and themselves and claim their fair share of production capacity — which, with size symmetry (as assumed here) is one-half. Formally

$$
f^{\prime}\left(\bar{E}^{\text {alt }}\right)=g^{\prime}\left(\bar{E}^{\text {alt }}\right) \text { and }
$$

$$
\bar{e}_{A E}^{a l t}=\bar{e}_{E M D E}^{a l t}=\frac{1}{2} \bar{E}^{a l t}
$$

where alt denotes altruistic optimization.

To compare altruistic with separate optimization, note that

$$
f^{\prime}\left(\frac{1}{2} \bar{E}^{\text {alt }}\right)>g^{\prime}\left(\frac{1}{2} \bar{E}^{\text {alt }}\right)
$$

which follows directly from the non-linearity assumptions (1) and (2) in the main text. Thus, at the altruistic equilibrium point, independently optimizing AEs would expand production capacity further, implying

$$
\bar{e}_{A E}^{i n d}>\bar{e}_{A E}^{a l t},
$$

i.e., AEs that optimize independently use their first-mover advantage to emit a larger amount of GHGs than they would emit with altruistic behavior. From (A3) and (A7) follows

$$
\bar{e}_{A E}^{i n d}+\bar{e}_{E M D E}^{i n d}>\bar{e}_{A E}^{a l t}+\bar{e}_{E M D E}^{a l t} .
$$

Hence, individual optimization results in higher overall GHG emissions than altruistic optimization.

\section{Strategic Optimization}

With strategic optimization, AEs anticipate that their emissions will impact EMDEs' subsequent emitting behavior. Formally, the AEs' cost function becomes

$$
C_{A E}=g\left(e_{A E}+e_{E M D E}\left(e_{A E}\right)\right) \text {, }
$$

which yields the first-order condition:

$$
f^{\prime}\left(\bar{e}_{A E}^{s t r}\right)=g^{\prime}\left(\bar{e}_{A E}^{s t r}+\bar{e}_{E M D E}^{s t r}\right)\left(1+\partial \bar{e}_{E M D E}^{s t r} / \partial \bar{e}_{A E}^{s t r}\right)
$$

where str denotes strategic optimization.

Instead of comparing the development benefit of emitting additional GHGs with the immediate cost that emissions generate as in (A1), strategic AEs compare the benefit with the 
cost of additional overall GHG emissions that their expansion of production capacity induces. From (A3) follows that the increase in overall emissions will be less than increase in AE emissions. At the same time, the increase in overall emissions will happen at a higher concentration of GHGs in the atmosphere, and will therefore be more costly per unit of emitted GHGs. Which of these effects dominates - and therefore whether strategic behavior implies more or less emissions than individual optimization - is ambiguous and depends on the model's parameterization. For the base specification used in the main text, the differences between individual and strategic optimization are minimal. 


\section{REFERENCES}

Acemoglu, D., U. Akcigit, D. Hanley, and W. Kerr (2016). Transition to Clean Technology. Journal of Political Economy 124(1), 52-104

Barrett, P. (2021). Can International Technological Diffusion Substitute for Coordinated Global Policies to Mitigate Climate Change? IMF Working Paper 2021/173 (Washington)

Barrett, S. (2016). Coordination vs. Voluntarism and Enforcement in Sustaining International Environmental Cooperation. Proceedings of the National Academy of Sciences, 113(51) 14515-14522

Bosetti, V., C. Carraro, E. De Cian, E. Massetti, and M. Tavoni (2013). Incentives and Stability of International Climate Coalitions: An Integrated Assessment. Energy Policy 55, 44-56.

Clarke, L., K. Jiang, K. Akimoto, M. Babiker, G. Blanford, K. Fisher-Vanden, J.-C. Hourcade, and others. (2014). Assessing Transformation Pathways. In: Climate Change 2014: Mitigation of Climate Change. Contribution of Working Group III to the Fifth Assessment Report of the Intergovernmental Panel on Climate Change. Cambridge, U.K. New York, NY, USA: Cambridge University Press.

Diringer, E. (2009). Technology Transfer in a New Global Climate Agreement. In: Climate Change Policy: Recommendations to Reach Consensus, 42-50. Brookings (Washington)

Gillingham, K., and J Stock (2018). The Cost of Reducing Greenhouse Gas Emissions. Journal of Economic Perspectives, 32(4), 53-72

International Monetary Fund (2017). The Effects of Weather Shocks on Economic Activity: How Can Low-income Countries Cope? World Economic Outlook 117-183 (October) (Washington).

(2019a). Building Resilience in Developing Countries Vulnerable to Large Natural Disasters. IMF Policy Paper (Washington).

(2019b). How to Mitigate Climate Change. Fiscal Monitor, 1-29. (October) (Washington).

(2020). Mitigating Climate Change - Growth- and Distribution-Friendly Strategies. World Economic Outlook 85-113 (April) (Washington). 
(2021). Proposal for an International Carbon Price Floor Among Large Emitters. Staff Climate Note 2021/001 (Washington).

IRENA (2021). Renewable Power Generation Costs in 2020. Abu Dhabi: International Renewable Energy Agency

James, R., F. Otto, H. Parker, E. Boyd, R. Cornforth, D. Mitchell and A. Myles (2014). Characterizing Loss and Damage from Climate Change. Nature Climate Change 4, 938-939

Miyamoto, M, and K. Takeuchi (2019). Climate Agreement and Technology Diffusion: Impact of the Kyoto Protocol on International Patent Applications for Renewable Energy Technologies. Energy Policy 129, 1331-38

Organization of Economic Cooperation and Development (2020). Climate Finance Provided and Mobilised by Developed Countries in 2013-18 (Paris)

Probst, B., S. Touboul, M. Glachant and A. Dechezleprêtre (2021). Global Trends in the Innovation and Diffusion of Climate Change Mitigation Technologies. Working Papers Hal-03190012, HAL

Rajan, R. (2021). A Global Incentive to Reduce Emissions. Project Syndicate (May)

Shahbaz, M. and Sinha, A. (2019). Environmental Kuznets Curve for CO2 Emissions: a Literature Survey. Journal of Economic Studies 46 (1), 106-168 